\title{
Synthesis, gastroprotective and acute toxicity of bio-isosteric derivative of diclofenac
}

\section{Dana Ameen ${ }^{1 *}$}

\begin{abstract}
Background and objective: Non-steroidal anti-inflammatory drugs (such as diclofenac1) had been widely prescribed for the treatment of different types of pain; however, they are not devoid of adverse effects. Therefore, synthesis of new bio-isosteric analogs $4 a-e$ of diclofenac1 with greater COX II selectivity and less gastrointestinal side effect is demanded. This study aimed to evaluate the acute toxicity and gastroprotective activity of the bio-isosteric derivative of diclofenac against ethanol-induced gastric ulceration in rats.

Methods: 2-Cumaranone 2 had been utilized to prepare amides 3a-e then after the bio-isosteric derivatives 4a-esynthesized from them then used to study the biological activity by testing whether high doses of the prototype compound $4 \mathrm{c}$ are toxic or not on albino mice and measuring the gastroprotective effect on albino rats. Rats were divided into four groups. Group 1 orally administered with Tween 20; group 2 was orally administered with $20 \mathrm{mg} / \mathrm{kg}$ esomeprazole; groups 3 and 4 received 100 and $200 \mathrm{mg} / \mathrm{kg}$ of the compound, respectively. Absolute ethanol was given orally to the groups, and rats were sacrificed after one hour.

Results: Few diarylethers 4a-ebio-isosteric to diclofenac had been prepared and fully characterized (including ${ }^{1} \mathrm{HNMR},{ }^{13} \mathrm{CNMR}$, and IR spectroscopy). Serum biochemical parameters were reported to be normal. Hematological analysis of kidney and liver did not elicit any remarkable changes in the treated group compared to the control group. Thus, the $50 \%$ oral lethal dose $\left(L D_{50}\right)$ for the male and female mice was greater than $5 \mathrm{~g} / \mathrm{kg}$ body weight. Anti-ulcer data showed a gastroprotective effect of the bio-isosteric diclofenac derivative $4 \mathrm{c}$ and presented the ulcer area inhibition, low stomach $\mathrm{pH}$, and preserve the mucous content.
\end{abstract}

Conclusion: Many bio-isosteric derivatives of diclofenac had been prepared with good yields. The synthesized derivative4c showed no toxicity, and the gastroprotective effect may possibly be due to the preservation of gastric wall mucus.

Keywords: NSAIDs; Diclofenac; Diarylether; Bio-isostere; Gastroprotective.

\section{Introduction}

The synthesis of diarylether derivatives (such as compounds 4a-e) had been studied in recent years, and numerous reviewers demonstrated that they possess anti-inflammatory, antimicrobial and anticancer activities. ${ }^{1-5}$ Moreover, the amides of diarylethers 4a-e prepared herein have close structural similarity to non-steroidal anti-inflammatory drugs (NSAIDs), ${ }^{6}$ especially diclofenac 1 which is one of the most commonly prescribed
NSAIDs (shown in the scheme 2), and these were also studied for their COX-inhibition activity. ${ }^{7}$ NSAIDs are class of medicines with anti-inflammatory, analgesic or anti-pyretic activities, due to their abilities to inhibit the cyclooxygenase enzyme (COX) isoforms I and II. ${ }^{8}$ NSAIDs are the most prescribed medications universally for the treatment of acute and chronic pain. ${ }^{9}$ The major adverse effects associated with NSAID therapy are gastrointestinal irritation and internal

${ }^{1}$ Department of Pharmaceutical Chemistry, College of Pharmacy, Hawler Medical University, Erbil, Iraq.

* Correspondence: dana.ameen@hmu.edu.krd 
bleeding. However, it would be fatal in a few cases. The gastrointestinal irritation is because of the inactivation of the COX I, while the desired clinical efficacy is due to the COX II inactivation. ${ }^{10-12}$ In order to counter the side effects of NSAIDs (such as diclofenac1), many prodrug approaches had been reported, ${ }^{13,14}$ though, bio-isosteric derivatives of diclofenac might also be useful. In the latter case, diarylether analogue 4a-e to diclofenac (diphenylamine, as shown in scheme 1) 1 could be prepared, and converting the carboxylic acid to a less acidic functionality such as an amide moiety to reduce the direct gastrointestinal irritation and indirect irritation due to greater selectivity to COX $11 .{ }^{6}$ The current study is conducted to evaluate the acute toxicity and gastroprotective activity of the bio-isosteric derivative of diclofenac against ethanolinduced gastric ulceration in rats.

\section{Methods}

This study design was of an experimental type with simple randomization assignments, in which the chemical changes to the diclofenac was assumed to lead to no changes in the toxicity outcomes of albino rats and expected to possess a gastroprotective effect. The study was conducted at the College of Pharmacy and College of Medicine between April and
September 2018.

\section{Chemistry}

The chemical reactions (as shown in scheme 1) had been carried out at the Organic and Pharmaceutical Chemistry Lab., at Hawler Medical University, College of Pharmacy. Commercially available reagents were used as received without purification. Analytical thin layer chromatography (TLC) was performed with plastic-backed TLC plates coated with silica $G / U V_{254}$, in a variety of solvents. The plates were visualized by UV light (254 nm). ${ }^{1} \mathrm{H}$, and ${ }^{13} \mathrm{C}$ NMR spectra were recorded on a BrukerUltra Shield 300 (300 $\mathrm{MHz}$ ) spectrometer. All chemical shifts $(\delta)$ are quoted in parts per million (ppm) relative to a calibration reference of the residual protic solvent; $\mathrm{CHCl}_{3}\left(\delta_{\mathrm{H}} 7.26, \mathrm{~s}\right)$ was used as the internal standard in ${ }^{1} \mathrm{H}$ NMR spectra, and ${ }^{13} \mathrm{C}$ NMR shifts were referenced using $\mathrm{CDCl}_{3}\left(\delta_{\mathrm{C}} 77.16, \mathrm{t}\right)$ with broadband decoupling and the $J$ values are measured in Hertz (Central Lab., University of Jordon). Melting points of the synthesized compounds were measured on the electrothermal melting point apparatus (Gallenkamp, UK) and are uncorrected. IR spectra were recorded on a JASCO, Japan (Pharmaceutical Chemistry Department, College of Pharmacy, Hawler Medical University/ Erbil).

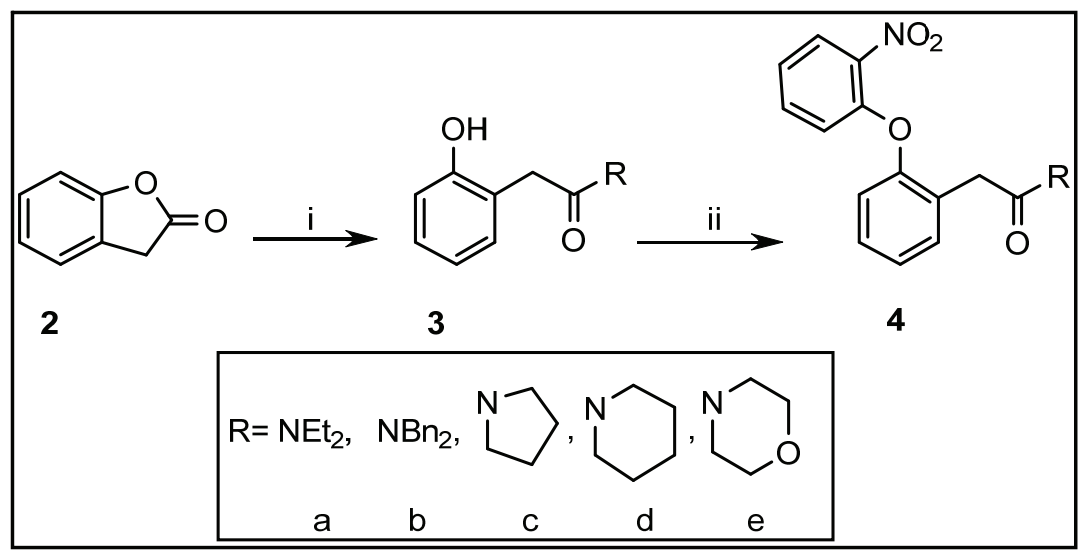

Scheme 1: Synthesis of bio-isosteric derivatives of diclofenac $4 a-e$.

Reaction conditions: i) amines $\mathrm{R}(1.5$ eq.), 2-cumaranone 2 (1 eq.), toluene $(0.1 \mathrm{M})$, reflux, 6 hours; ii) acetamides 3a-e (1 eq.), 1-fluoro-2-nitrobenzene (FNB)5 (10 eq.), $\mathrm{K}_{2} \mathrm{CO}_{3}$ (2.5 eq.), DMSO (0.1 M), $25^{\circ} \mathrm{C}, 24$ hours. $^{15}$ 


\subsection{General procedure for the synthesis} of amides 3a-e

To a solution of 2-coumaranone2(1 eq.) in toluene $(0.1 \mathrm{M})$ was added the amineR (1.5eq.). The resulting solution was stirred at $110^{\circ} \mathrm{C}$ for 6 hours, after which it was allowed to cool, acidified (1 $\mathrm{M} \mathrm{HCl})$, and extracted with ethyl acetate. The combined organic layers were washed with distilled water and brine, dried $\left(\mathrm{MgSO}_{4}\right)$, filtered and the solvent evaporated invacuo to afford the pure amide directly or after flash column chromatography.

1.2 General procedure for the synthesis of bio-isosteric diarylethers 4a-e

To a solution of the prepared amides3a-e (1 eq.) in DMSO $(0.1 \mathrm{M})$ was added potassium carbonate (2.5 eq.), and the resulting solution was stirred at $25^{\circ} \mathrm{C}$ for 30 minutes. 1-Fluoro-2-nitrobenzene FNB 5 (10 eq.) was added, and the reaction stirred for 24 hours at $25^{\circ} \mathrm{C}$. After which, the mixture was acidified with hydrochloric acid solution $(1 \mathrm{M})$. The product was extracted with ethyl acetate, and the combined organic layers were washed with distilled water, brine, dried $\left(\mathrm{MgSO}_{4}\right)$, filtered and the solvent evaporated invacuo to afford the crude residue which was purified by flash column chromatography.

\section{Biological study}

\subsection{Acute toxicity study}

To determine a safe range of doses for the bio-isosteric derivatives of diclofenac, toxicity test was carried out as previously described. ${ }^{16}$ Compound $4 \mathrm{~b}$ selected as the prototype as it showed the highest COX II inhibition activity. In brief, 36 mice, including 18 females and 18 males were divided into three groups categorized as the vehicle (10\% Tween 20$)$, low dose of bio-isosteric derivative of diclofenac $4 \mathrm{c}$ (2 $\mathrm{g} / \mathrm{kg})$ and high dose of bio-isosteric derivative of diclofenac $4 \mathrm{c}(5 \mathrm{~g} / \mathrm{kg})$. The mice were fasted for $16 \mathrm{~h}$ prior to the dosing (water was accessible except for the last two h). After the dosing, food was withdrawn for another one to three hours. Any signs of toxicities and mortality were documented during the next two weeks. On day 15, the animals were sacrificed, and blood serum samples were collected for hematological analysis.

\subsection{Ethanol-induced gastric ulceration}

Healthy male albino rats (150-180 g, 6-8 weeks old) were obtained from the Animal House Unit, College of Medicine, Hawler Medical University. The animals were allowed access to standard rat pellets and RO (reverse osmosis) water. Entirely animal experiments were conceded in agreement with the prior approval from the Ethics committee of College of Pharmacy, Hawler Medical University (Ethics No. 181112/81)Date. The preventive effect of bio-isosteric derivative of diclofenac $4 \mathrm{c}$ against superficial hemorrhagic mucosal lesions was investigated in the normal rats. Prior to the experiment, albino male rats were fasted for 24 hours (water was accessible except for the last two hours). Twenty four rats were divided randomly into four groups of 6 rats each and pre-treated accordingly (Table 1 ). The rats were sacrificed one hour later with xylazine and ketamine, and their stomachs were immediately excised. The stomach of each rat was dissected along the greater curvature, and $\mathrm{pH}$-meter titration with $0.1 \mathrm{~N}$ $\mathrm{NaOH}$ was used to analyze the hydrogen ion concentration in the gastric contents expressed in $\mathrm{mEq} / \mathrm{l}$ value. Then, a glass slide was applied to gently scrape the gastric mucosa of the rats followed by the weighing of the obtained mucus with a precision electronic balance. ${ }^{16}$

Table 1: The experimental design and specifications of the animal study.

\begin{tabular}{llll}
\hline Groups & Description & Pre-treatment & Treatment \\
\hline Group 1 & Ulcer control & $10 \%$ Tween $20(5 \mathrm{ml} / \mathrm{kg})$ & absolute ethanol \\
Group 2 & Treatment control & Esomeprazole $(20 \mathrm{mg} / \mathrm{kg})$ & absolute ethanol \\
Group 3 & Experimental group1 & LD $(100 \mathrm{mg} / \mathrm{kg})$ & absolute ethanol \\
Group 4 & Experimental group2 & $\mathrm{HD}(200 \mathrm{mg} / \mathrm{kg})$ & absolute ethanol \\
\hline \hline
\end{tabular}




\subsection{Macroscopic analysis of lesions}

The hemorrhagic damage of the stomach was determined by the assessment of the luminal surface. The ulcer inhibition percentage $(1 \%)$ of each pre-treatment was calculated using a planimeter (10x $10 \mathrm{~mm}^{2}$ ) and a dissecting microscope (1.8x) where UC and UT were the ulcer area of the control and treated group, respectively. The measurement of the ulcer area was performed as previously described in detail by Abdelwahab et al. ${ }^{17}$

$(I \%)=[($ UAcontrol - UAtreated $) \div$ UAcontrol $] \times 100$.

\section{Statistical analysis}

All values were reported as mean \pm SEM.

The statistical analysis was done using the statistical package for the social sciences (version 23). One-way ANOVA was used to compare means. A value of $P<0.05$ was considered significant.

\section{Results}

The acetamides 3a-e had been prepared from 2-cumaranone 2 and corresponding amines $R$ with a good yield and fully characterized by different spectroscopic methods, as shown in Tables 2 and 3 . After the successful preparation of the amide substrates $3 a-e$, their reaction with FNB 5 afforded the bio-isosteric diarylether derivatives $4 a-e$ in their maximum percents of yield, as shown in Tables 2 and 3.

Table 2: Physical data and isolated yields of the amides 3a-e and bio-isosteric diarylethers 4a-e.

\begin{tabular}{lcccc}
\hline Entry & Yield $\mathbf{( \% )}$ & Colour & Melting point ${ }^{\circ} \mathbf{C}$ & $\begin{array}{c}\boldsymbol{R}_{\mathrm{f}}(\mathbf{3 0} \% \text { EtOAc in } \\
\text { petroleum ether })\end{array}$ \\
\hline 3a & 96 & Colorless & $88-90$ & 0.56 \\
3b & 95 & Yellow & $139-141$ & 0.69 \\
3c & 89 & Colorless & $120-122$ & 0.52 \\
3d & 98 & Yellow & $107-109$ & 0.48 \\
3e & 87 & Yellow & $123-125$ & 0.37 \\
4a & 100 & Yellow & oily substance & 0.74 \\
4b & 100 & Yellow & oily substance & 0.48 \\
4c & 100 & Yellow & oily substance & 0.41 \\
4d & 100 & Yellow & 74-76 & 0.57 \\
4e & 100 & Yellow & oily substance & 0.39 \\
\hline
\end{tabular}


Table 3: Diagnostics peaks and values in IR, ${ }^{1} \mathrm{HNMR}$, and ${ }^{13} \mathrm{CNMR}$ of the amides $3 a-e$ and bio-isosteric diarylethers $4 a-e$.

\begin{tabular}{|c|c|c|c|}
\hline Comp. & $\operatorname{IR}\left(\mathrm{cm}^{-1}\right)$ & ${ }^{1} \mathrm{H}$ NMR(ppm) & ${ }^{13} \mathrm{C}$ NMR(ppm) \\
\hline $3 a$ & $\begin{array}{l}1618 \text { (C=O stretching), } \\
3173 \text { (OH stretching), } \\
1090 \text { (C-O stretching) }\end{array}$ & $\begin{array}{c}1.13(\mathrm{t}, 3 \mathrm{H}, J=7.5 \mathrm{~Hz}), \\
1.29(\mathrm{t}, 3 \mathrm{H}, J=6.0 \mathrm{~Hz}), \\
3.39(\mathrm{q}, 2 \mathrm{H}, J=6.0 \mathrm{~Hz}), \\
3.50(\mathrm{q}, 2 \mathrm{H}, J=7.5 \mathrm{~Hz}) \\
3.71(\mathrm{~s}, 2 \mathrm{H}), 10.47(\mathrm{~s}, 1 \mathrm{H})\end{array}$ & $\begin{array}{c}\text { 13.05, 14.94 }\left(\mathrm{CH}_{3}\right), \\
\text { 37.06, 41.47, } \\
\text { 43.67 }\left(\mathrm{CH}_{2}\right)\end{array}$ \\
\hline $3 b$ & $\begin{array}{c}\text { (C=O stretching), } \\
3064 \text { (O-H stretching), } \\
1477 \text { (C-O stretching) }\end{array}$ & $\begin{array}{l}3.81(\mathrm{~s}, 2 \mathrm{H}), 4.63(\mathrm{~s}, 2 \mathrm{H}) \\
4.64(\mathrm{~s}, 2 \mathrm{H}), 10.07(\mathrm{~s}, 1 \mathrm{H})\end{array}$ & $\begin{array}{l}37.18,49.33 \\
51.26,\left(\mathrm{CH}_{2}\right)\end{array}$ \\
\hline $3 c$ & $\begin{array}{l}1610 \text { (C=O stretching), } \\
2959 \text { (OH stretching), } \\
1094 \text { (C-O stretching) }\end{array}$ & $\begin{array}{c}1.89 \text { (pent, } 2 \mathrm{H}, J=6.0 \mathrm{~Hz}), \\
2.01 \text { (pent, } 2 \mathrm{H}, J=6.0 \mathrm{~Hz}), \\
3.48(\mathrm{t}, 2 \mathrm{H}, J=7.5 \mathrm{~Hz}), \\
3.68(\mathrm{t}, 2 \mathrm{H}, J=6.0 \mathrm{~Hz}) \\
3.70(\mathrm{~s}, 2 \mathrm{H}), 10.37(\mathrm{~s}, 1 \mathrm{H})\end{array}$ & $\begin{array}{c}24.53,26.12,39.03, \\
46.34,47.77\left(\mathrm{CH}_{2}\right)\end{array}$ \\
\hline $3 d$ & $\begin{array}{l}1616 \text { (C=O stretching), } \\
3166 \text { (OH stretching), } \\
1039 \text { (C-O stretching) }\end{array}$ & $\begin{array}{c}1.52-1.63(\mathrm{~m}, 6 \mathrm{H}), \\
3.55(\mathrm{t}, 2 \mathrm{H}, \mathrm{J}=6.0 \mathrm{~Hz}), \\
3.61(\mathrm{t}, 2 \mathrm{H}, \mathrm{J}=6.0 \mathrm{~Hz}) \\
3.73(\mathrm{~s}, 2 \mathrm{H}), 9.87(\mathrm{~s}, 1 \mathrm{H})\end{array}$ & $\begin{array}{c}\text { 24.25, 25.36, } \\
26.52,36.41,43.45, \\
48.16,\left(\mathrm{CH}_{2}\right)\end{array}$ \\
\hline $3 e$ & $\begin{array}{l}1615 \text { (C=O stretching), } \\
2931 \text { (OH stretching), } \\
1092 \text { (C-O stretching) }\end{array}$ & $\begin{array}{c}3.65-3.68(\mathrm{~m}, 8 \mathrm{H}), \\
3.74(\mathrm{~s}, 2 \mathrm{H}), 9.56(\mathrm{~s}, 1 \mathrm{H})\end{array}$ & $\begin{array}{r}36.31,42.59,47.29 \\
66.51,66.65\left(\mathrm{CH}_{2}\right)\end{array}$ \\
\hline $4 a$ & $\begin{array}{c}1638 \text { (C=O stretching), } \\
1098 \text { (C-O stretching), } \\
1526,1368 \text { (N-O stretching) }\end{array}$ & $\begin{array}{c}0.97(\mathrm{t}, 3 \mathrm{H}, J=7.5 \mathrm{~Hz}), \\
1.09(\mathrm{t}, 3 \mathrm{H}, \mathrm{J}=7.5 \mathrm{~Hz}), \\
3.25-3.35(\mathrm{~m}, 4 \mathrm{H}), \\
3.71(\mathrm{~s}, 2 \mathrm{H})\end{array}$ & $\begin{array}{c}\text { 12.74, 14.02 }\left(\mathrm{CH}_{3}\right), \\
34.25,40.31 \\
42.33\left(\mathrm{CH}_{2}\right)\end{array}$ \\
\hline $4 b$ & $\begin{array}{c}1644 \text { (C=O stretching), } \\
1079 \text { (C-O stretching), } \\
1523,1349 \text { (N-O stretching) }\end{array}$ & $\begin{array}{c}3.90(\mathrm{~s}, 2 \mathrm{H}), 4.55(\mathrm{~s}, 2 \mathrm{H}) \\
4.59(\mathrm{~s}, 2 \mathrm{H})\end{array}$ & $\begin{array}{c}34.80,48.65 \\
50.38\left(\mathrm{CH}_{2}\right)\end{array}$ \\
\hline 4c & $\begin{array}{c}1636 \text { (C=O stretching), } \\
1247 \text { (C-N stretching), } \\
1098 \text { (C-O stretching), } \\
1522,1345 \text { (N-O stretching) }\end{array}$ & $\begin{array}{c}1.69-1.92(\mathrm{~m}, 4 \mathrm{H}), \\
3.31(\mathrm{t}, 2 \mathrm{H}, \mathrm{J}=6.0 \mathrm{~Hz}), \\
3.43(\mathrm{t}, 2 \mathrm{H}, \mathrm{J}=7.5 \mathrm{~Hz}), \\
3.67(\mathrm{~s}, 2 \mathrm{H})\end{array}$ & $\begin{array}{r}24.43,26.15,35.89, \\
45.93,46.89\left(\mathrm{CH}_{2}\right)\end{array}$ \\
\hline $4 d$ & $\begin{array}{c}1642 \text { (C=O stretching), } \\
1068 \text { (C-O stretching), } \\
1584,1350 \text { (N-O stretching) }\end{array}$ & $\begin{array}{c}1.48-1.57(\mathrm{~m}, 4 \mathrm{H}), \\
1.65-1.70(\mathrm{~m}, 2 \mathrm{H}), \\
3.52(\mathrm{t}, 2 \mathrm{H}, \mathrm{J}=6.0 \mathrm{~Hz}), \\
3.61(\mathrm{t}, 2 \mathrm{H}, \mathrm{J}=6.0 \mathrm{~Hz}), \\
3.86(\mathrm{~s}, 2 \mathrm{H})\end{array}$ & $\begin{array}{c}\text { 24.37, 25.45, } \\
26.16,34.24,42.88, \\
46.99\left(\mathrm{CH}_{2}\right)\end{array}$ \\
\hline $4 e$ & $\begin{array}{c}1642 \text { (C=O stretching), } \\
1068 \text { (C-O stretching), } \\
1584,1350 \text { (N-O stretching); }\end{array}$ & $\begin{array}{c}3.47-352(\mathrm{~m}, 8 \mathrm{H}), \\
3.71(\mathrm{~s}, 2 \mathrm{H})\end{array}$ & $\begin{array}{c}34.09,42.25,46.37, \\
66.64,66.79\left(\mathrm{CH}_{2}\right)\end{array}$ \\
\hline
\end{tabular}


In the acute toxicity study (high doses), all mice survived and did not evident any sign of toxicity and abnormality at 2 and 5 $\mathrm{g} / \mathrm{kg}$ dosage. For a duration of 14 days, there were no behavioral changes, and no abnormal signs were observed. As shown in Table 4 and 5 , the serum biochemical parameters were reported to be normal. Hematological analysis of kidney and liver did not elicit any remarkable changes in the treated group compared to the control group. Thus, the $50 \%$ oral lethal dose $\left(L D_{50}\right)$ for the male and female mice was greater than $5 \mathrm{~g} / \mathrm{kg}$ body weight. Regarding the Macroscopic results of the antiulcer study; Table 6 shows that after treatment with esomeprazole (positive control), the acidity was significantly attenuated while rats pre-treated with diclofenac derivative at high dose and low dose caused slight elevation of the stomach $\mathrm{pH}$ however the gastric mucus content was indeed washed-out in animals pre-treated with ethanol.

Table 4: Effect of bio-isosteric derivative of diclofenac on serum biochemical analysis (renal function test).

\begin{tabular}{lcccccc}
\hline $\begin{array}{l}\text { Animal } \\
\text { groups }\end{array}$ & $\begin{array}{c}\text { Urea } \\
\text { (mg/dL) }\end{array}$ & $\begin{array}{c}\text { Creatinin } \\
(\mathbf{m g} / \mathbf{d L})\end{array}$ & $\begin{array}{c}\text { Uric acid } \\
(\mathbf{m g} / \mathbf{d L})\end{array}$ & $\begin{array}{c}\text { Calcium } \\
(\mathbf{m g} / \mathbf{d L})\end{array}$ & $\begin{array}{c}\text { Phosphorus } \\
(\mathbf{m g} / \mathbf{d L})\end{array}$ & $\boldsymbol{P}$ value \\
\hline Vehicle & $43.5 \pm 0.4$ & $0.42 \pm 0.1$ & $5.7 \pm 0.4$ & $9.95 \pm 0.6$ & $8.1 \pm 0.4$ & \\
LD $\mathbf{( 2} \mathbf{~ g / k g )}$ & $44.33 \pm 0.3$ & $0.39 \pm 0.7$ & $5.6 \pm 0.5$ & $9.97 \pm 0.7$ & $8.37 \pm 0.7$ & 0.251 \\
HD (5 $\mathbf{~} / \mathbf{k g})$ & $43.00 \pm 0.8$ & $0.44 \pm 0.03$ & $5.9 \pm 0.5$ & $10.00 \pm 0.4$ & $7.97 \pm 0.3$ & 0.432 \\
\hline
\end{tabular}

Values expressed as mean \pm SEM. The results did not show any significant difference between groups.

Table 5: Effect of bio-isosteric derivative of diclofenac on serum biochemical analysis (Liver function test).

\begin{tabular}{lcccccc}
\hline $\begin{array}{l}\text { Animal } \\
\text { groups }\end{array}$ & $\begin{array}{c}\text { Liver biochemical parameters } \\
\text { Total Bilirubin } \\
(\mathbf{m g} / \mathbf{d L})\end{array}$ & $\begin{array}{c}\text { Direct Bilirubin } \\
(\mathbf{m g} / \mathbf{d L})\end{array}$ & AST (U/L) & ALT (U/L) & ALP (U/L) & \\
\hline Vehicle & $0.05 \pm 0.4$ & $0.01 \pm 0.9$ & $183.9 \pm 1.8$ & $37.5 \pm 0.3$ & $115.5 \pm 0.1$ & \\
LD $(\mathbf{2} \mathbf{~ g / k g )}$ & $0.06 \pm 0.5$ & $0.01 \pm 0.5$ & $177 \pm 1.2$ & $40.7 \pm 0.1$ & $137.3 \pm 0.4$ & 0.371 \\
HD (5 $\mathbf{~ g / k g ) ~}$ & $0.05 \pm 1.9$ & $0.01 \pm 0.1$ & $189.7 \pm 1.5$ & $35 \pm 0.4$ & $106 \pm 0.1$ & 0.402 \\
\hline
\end{tabular}

Values expressed as mean \pm SEM. The results did not show any significant difference between groups. ALT: alanine aminotransferase; AST: aspartate aminotransferase; ALP: alkaline phosphatase.

Table 6: Antiulcer activity of bio-isosteric derivative of diclofenac against ethanol-induced gastric injury.

\begin{tabular}{|c|c|c|c|c|c|c|}
\hline Animal group & $\begin{array}{l}\text { Pre-treatment } \\
(5 \mathrm{ml} / \mathrm{kg})\end{array}$ & $\begin{array}{c}\text { Ulcer area } \\
\left(\mathrm{mm}^{2}\right)\end{array}$ & $\begin{array}{c}\text { Inhibition } \\
\text { (\%) }\end{array}$ & $\begin{array}{c}\text { Mucus } \\
\text { weight (g) }\end{array}$ & $\begin{array}{c}\mathrm{pH} \\
(\mathrm{mEq} / \mathrm{l})\end{array}$ & $P$ value \\
\hline $\begin{array}{l}\text { Vehicle } \\
\text { (Ulcer Positive) }\end{array}$ & $10 \%$ Tween 20 & $220.8 \pm 0.3$ & $\ldots$ & $0.34 \pm 0.1$ & $3.7 \pm 0.6$ & \\
\hline $\begin{array}{l}\text { Control } \\
\text { (Ulcer Negative) }\end{array}$ & $\begin{array}{c}20 \mathrm{Mg} / \mathrm{kg} \\
\text { Esomeprazole }\end{array}$ & $55.2 \pm 0.1^{*}$ & $95.1^{*}$ & $1.16 \pm 0.9^{*}$ & $\underset{*}{6.7 \pm 0.2}$ & $<0.001$ \\
\hline Low Dose & $\begin{array}{l}100 \mathrm{mg} / \mathrm{kg} \\
\text { derivative }\end{array}$ & $74.4 \pm 0.2^{*}$ & $63.5^{*}$ & $0.8 \pm 0.4^{*}$ & $\underset{*}{5.5 \pm 0.1}$ & $<0.001$ \\
\hline High Dose & $\begin{array}{l}200 \mathrm{mg} / \mathrm{kg} \\
\text { derivative }\end{array}$ & $129.6 \pm 0.3^{*}$ & $53.8^{*}$ & $0.7 \pm 0.5^{*}$ & $5.7 \pm 0.5$ & $<0.001$ \\
\hline
\end{tabular}

The values are expressed as the mean \pm SEM. $\left(^{*}\right)$ Indicates significance compared to the ulcer positive group 
The administration of ethanol to the rats induced obvious hemorrhagic lesions in the gastric walls, as shown in Figure 1, while rats treated with diclofenac derivative and esomeprazole showed fewer areas of gastric ulcer formation in comparison with the vehicle control group. It is worthy to note that the treatment helped to flatten some of the gastric mucosal folds in rat's' stomachs.

\section{Discussion}

Ameen had focused on developing the first example of chiral version of Truce-smiles rearrangement, and the amide substrates 3a-ehad been attempted. In his work, the diarylethers 4a-e documented that had significant COX inhibition, and the compound 4c showed maximum inhibition against COX II (70\%). ${ }^{15}$ Therefore, the amides4a-e (derivatives of diclofenac 1 , shown in scheme 2) had been prepared to apply the same procedure established by Snape and Ameen. ${ }^{6}$ As it can be shown from Tables 2 and 3 , their physical properties and diagnostic peaks imply same documented in the literature. ${ }^{6,15}$

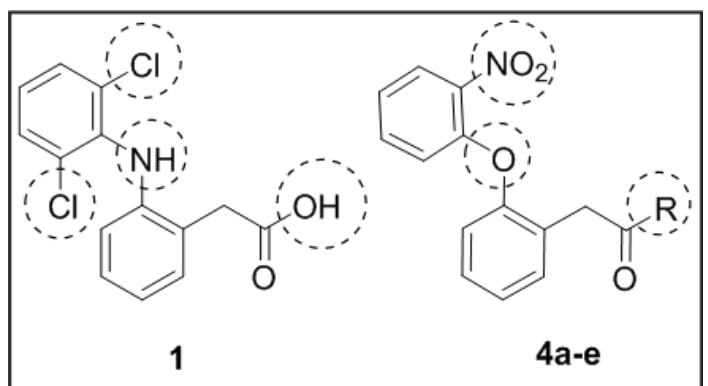

Scheme 2: The structure of diclofenac 1 and its bio-isosteric derivatives $4 a-e$.

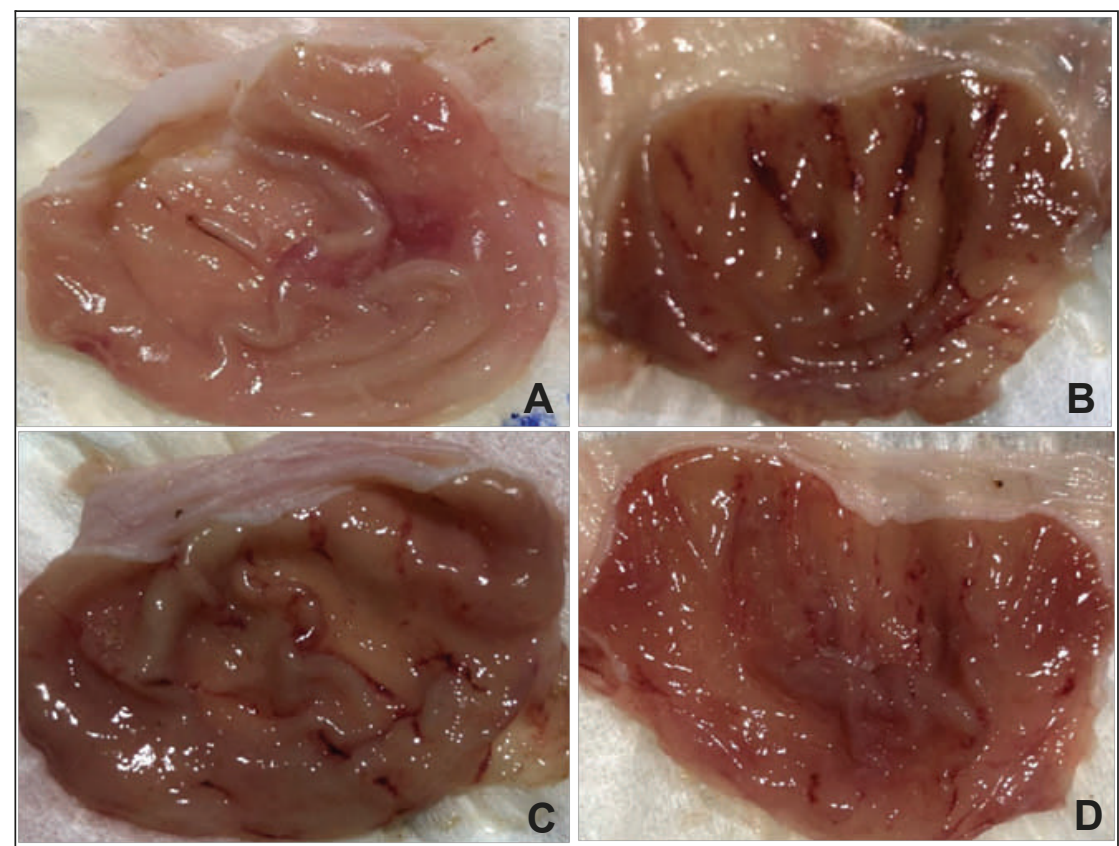

Figure 1: Effect of bio-isosteric derivative of diclofenac on macroscopic appearance of the gastric mucosa. The esomeprazole group shows mild injuries in comparison to the ulcer control group (A). Severe injuries are observed in the gastric mucosa of the ulcer control group (B). The HD group shows mild injuries to the gastric mucosa (C), while LD group shows moderate injuries in the gastric mucosa and flattened of the mucosal folds (D). 
For the synthesis of the amides of the diarylethers $4 a-e$, the optimized protocol (using 10 equivalents of 1-fluoro-2nitrobenzene FNB5) had been utilized to get $100 \%$ yield, and with no rearrangement products (compounds 6 and 7 , demonstrated in scheme 3 ), as illustrated in Tables 2 and $3 .{ }^{6}$ Snape and Ameen found that by increasing the number of molar equivalents of FNB5 from 2.0 to 5.0 and to 10.0 equivalents, the amount of diarylethers 4 a-e also increased, at all temperatures studied $(25,60$ and $100{ }^{\circ} \mathrm{C}$ ), with no rearranged products 6 and 7 , as shown in scheme 3 . They provide the exact explanation for this occurrence that certain counter ions rendering the electron-rich enolate of diarylethers $4 a-e$ formed during the first stage of the reaction and unable to react further with FNB 5 to rearrange and givethe rearranged Truce-Smiles products such as 6 and $7 .^{6}$ Serum biochemical parameters of acute toxicity test were normal, and the hematological analysis of kidney and liver functions parameters did not elicit any remarkable changes in the treated group compared to the control group which means, that the $50 \%$ oral lethal dose $\left(\operatorname{LD}_{50}\right)$ for the male and female mice was greater than $5 \mathrm{~g} / \mathrm{kg}$ body weight. The presented data thus agrees with previously published results in different animal species like mice, rats, pigs. $^{18}$ Moreover, the results of the present study showed that the bio-isosteric derivative of diclofenac $4 c$ possessed an anti-ulcer activity against ethanol-induced hemorrhagic mucosal lesions in rats. The prototype derivative $4 \mathrm{c}$ increased the gastric wall mucus. Indeed, the gastroprotective effect of the chemical compounds appeared to be mediated partially through the protection of gastric mucus secretion. ${ }^{19}$ Alterations in gastric motility are chief focus points in the prevention of experimental gastric lesions. The results of the current study showed an increase in the flattening of the stomach mucosal folds, which suggests that the gastroprotective effect of the diclofenac derivative was due to a decrease in gastric motility. ${ }^{20}$ The mechanism of the anti-ulcer activity could be through increasing the cyclooxygenase enzymes that exist in two isoforms (COX I and COX II), which are the key factors for the synthesis of prostaglandins that have been shown to inhibit gastric secretion, stimulate bicarbonate secretion, and increase gastric blood volume. ${ }^{21}$ COX $\mathrm{I}$ is constitutively expressed in the gastrointestinal tract in large quantities and has been suggested to maintain mucosal integrity through continuous generation of prostaglandins that are important in the prevention and maintenance of gastric mucosal integrity and ulcer healing. However, diclofenac1 is a well-known non-steroidal antiinflammatory drug (NSAID), which acts by potent inhibition of both cyclooxygenase isoenzymes, COX I and COX II. ${ }^{22}$ Therefore, depending on the results of this<smiles>[R]C(=O)Cc1ccccc1O</smiles>

Scheme 3: The reaction of 10 equivalents of FNB 5 with the amides $3 a-e$. 
study, the gastroprotective effect of the bioisosteric derivative $4 \mathrm{c}$ of diclofenac might be due to its cyclooxygenase lowering activity, however, further studies need to be done to confirm that expectation.

\section{Conclusion}

Many bio-isosteric derivatives of diclofenac had been prepared with good yields, as shown in Tables 1 and 3 . The extra equivalents of FNB 5 were helpful in affording the prepared products in their maximum yields $(100 \%)$. The synthesized derivative $4 \mathrm{c}$ is not toxic up to $5 \mathrm{~g} / \mathrm{kg}$, and it possesses a gastroprotective effect. An increase in the mucus results in low ulcerogenic activity of 4c, and it may involve both low direct cytotoxicity due to a decrease in an aggressive factor (acid) and protective effect against the development of gastric lesions through an increase in a protective factor (mucus).

\section{Competing interests}

The author declares no competing interests.

\section{References}

1. Bedos-Belval F, Rouch A, Vanucci-Bacqué C, Baltas M. Diaryl ether derivatives as anticancer agents-a review. Med Chem Comm 2012; 3(11):1356-72.

2. Sriram D, Yogeeswari P, Devakaram RV. Synthesis, in vitro and in vivo antimycobacterial activities of diclofenac acid hydrazones and amides. Bioorg Med Chem 2006; 14(9):3113-8.

3. Inoue T, Anai S, Onishi S, Miyake M, Tanaka N, Hirayama A, et al. Inhibition of COX-2 expression by topical diclofenac enhanced radiation sensitivity via enhancement of TRAIL in human prostate adenocarcinoma xenograft model. BMC urology 2013; 13(1):1.

4. Habeeb AG, Praveen Rao P, Knaus EE. Design and synthesis of 4, 5-diphenyl-4-isoxazolines: novel inhibitors of cyclooxygenase-2 with analgesic and antiinflammatory activity. J Med Chem 2001; 44(18):2921-7.

5. Ameen D, Snape TJ. Chiral 1, 1-diaryl compounds as important pharmacophores. Med Chem Comm 2013; 4(6):893-907.

6. Ameen D, Snape TJ. Developing the Scope of $\mathrm{O} \rightarrow \mathrm{C}$ Aryl Migrations: Exploring Amide Substrates as Potential Precursors for Asymmetric Reactions. Eur J Org Chem 2014; 2014(9):1925-34.
7. Al-Hourani BJ, Sharma SK, Mane JY, Tuszynski $\mathrm{J}$, Baracos V, Kniess T, et al. Synthesis and evaluation of 1, 5-diaryl-substituted tetrazoles as novel selective cyclooxygenase-2 (COX-2) inhibitors. Bioorg Med Chem Lett 2011; 21(6):1823-6.

8. Hawkey C. COX-1 and COX-2 inhibitors. Best Pract Res Clin Gastroenterol 2001; 15(5):80120.

9. Barkin RL, Beckerman M, Blum SL, Clark FM, Koh E-K, Wu DS. Should nonsteroidal antiinflammatory drugs (NSAIDs) be prescribed to the older adult? Drugs Aging 2010; 27(10):77589.

10. Cryer B. NSAID-associated deaths: the rise and fall of NSAID-associated GI mortality. Am J Gastroenterol 2005; 100(8):1694.

11. James MW, Hawkey CJ. Assessment of non-steroidal anti-inflammatory drug (NSAID) damage in the human gastrointestinal tract. Br J Clinical Pharmacol 2003; 56(2):146-55.

12. Naesdal J, Brown K. NSAID-associated adverse effects and acid control aids to prevent them. Drug Saf 2006; 29(2):119-32.

13. Halen PK, Murumkar PR, Giridhar R, Yadav MR. Prodrug designing of NSAIDs. Mini Rev Med Chem 2009; 9(1):124-39.

14. Iqbal Z, Khan R, Nasir F, KHAN JA, Rashid A, Khan $A$, et al. Preparation and in-vitro in-vivo evaluation of sustained release matrix diclofenac sodium tablets using PVP-K90 and natural gums. Paki J Pharm Sci 2011; 24(4).

15. Ameen $\mathrm{DMH}$. Constructing chiral centres via $\mathrm{O} \rightarrow$ C aryl and acyl migrations: exploring reaction potential: University of Central Lancashire; 2014.

16. Hajrezaie M, Golbabapour S, Hassandarvish P, Gwaram NS, Hadi AHA, Ali HM, et al. Acute toxicity and gastroprotection studies of a new schiff base derived copper (II) complex against ethanol-induced acute gastric lesions in rats. PloS One 2012; 7(12):e51537.

17. Abdelwahab SI, Mohan S, Abdulla MA, Sukari MA, Abdul AB, Taha MME, et al. The methanolic extract of Boesenbergia rotunda (L.) Mansf. and its major compound pinostrobin induces anti-ulcerogenic property in vivo: possible involvement of indirect antioxidant action. J Ethnopharmacol 2011; 137(2):963-70.

18. Cevc G, Blume G. New, highly efficient formulation of diclofenac for the topical, transdermal administration in ultradeformable drug carriers, Transfersomes. Biochimica et Biophysica Acta (BBA)-Biomembranes 2001; 1514(2):191-205.

19. Salga MS, Ali HM, Abdulla MA, Abdelwahab SI. Gastroprotective activity and mechanism of novel dichlorido-zinc (II)-4-(2(5-methoxybenzylideneamino) ethyl) piperazin1-iumphenolate complex on ethanol-induced gastric ulceration. Chemico-Biological Interactions 2012; 195(2):144-53. 
20. Abdulla MA, Ahmed KA-A, Al-Bayaty $F H$, Masood Y. Gastroprotective effect of Phyllanthus niruri leaf extract against ethanol-induced gastric mucosal injury in rats. African Journal of Pharmacy and Pharmacology 2010; 4(5):226-30.

21. Halter F, Tarnawski A, Schmassmann A, Peskar B. Cyclooxygenase 2-implications on maintenance of gastric mucosal integrity and ulcer healing: controversial issues and perspectives. Gut 2001; 49(3):443-53.

22. Kirchheiner J, Meineke I, Steinbach N, Meisel C, Roots I, Brockmöller J. Pharmacokinetics of diclofenac and inhibition of cyclooxygenases 1 and 2: no relationship to the CYP2C9 genetic polymorphism in humans. $\mathrm{Br} \mathrm{J}$ Clin Pharmacol 2003; 55(1):51-61. 